\title{
RELATIONSHIP BETWEEN STRATEGIC PROCESSES AND CHARACTERISTICS OF MANAGERS AND COMPANIES: CASE OF FIVE STAR HOTELS IN KYRENIA
}

DOI: 10.17261/Pressacademia.2020.1269

PAP- V.11-2020(41)-p.211-215

\section{Mete Girgen}

International Final University, Tourism and Hospitality Department, Girne, Northern Cyprus. mete.girgen@final.edu.tr, ORCID: 0000-0003-2709-5639

To cite this document

Girgen, M., (2020). Relationship between strategic processes and characteristics of managers and companies: case of five star hotels in Kyrenia. PressAcademia Procedia (PAP), V.11, p. 211-215

Permanent link to this document: http://doi.org/10.17261/Pressacademia.2020.1269

Copyright: Published by PressAcademia and limited licensed re-use rights only

\begin{abstract}
Purpose- The purpose of this study is to show the importance of strategic decision-making processes and goals of companies. These terms are directly related to any company's success or survival factors. Effective decisions can affect companies positively, or if there are any problems in these decision-making activities, there may be adverse effects for companies. In this study, the relationship between Strategic Process (Decision Making and Objectives) and the Characteristics of Managers and Companies was investigated.

Methodology- Five-star hotels in Northern Cyprus were used as an example for research. In the methodology section, the researcher used some questionnaires for the research participants and the results were analyzed with the SPSS (version 23) program.

Findings- In the study, there is a theoretical framework based on hypotheses. The results of the study showed that there is a strong relationship between the strategic process and the characteristics of managers and companies.

Conclusion- There is a strong relationship with the goals of companies and the characteristics of managers and companies; it has been determined that there is a strong relationship between the strategic decision making process and the determination of the targets and the characteristics of the managers and companies.
\end{abstract}

Keywords: Manager Characteristics, Company Characteristics, Decision Making, Goals, Strategic Process JEL Codes: L83, O15, L10

\section{STRATEJIK SÜREÇLER ILE YÖNETiCi VE ŞIRKETLERIN ÖZELLiKLERI ARASINDAKi iLIŞKI: GIRNE'DEKi BEŞ YILDIZLI OTELLER ÖRNEĞi}

\section{ÖZET}

Amaç- Bu çalışmanın amacı, şirketlerin stratejik karar alma süreçlerinin ve hedeflerinin önemini göstermektir. Bu terimler herhangi bir şirketin başarı veya hayatta kalma faktörleriyle doğrudan ilişkilidir. Etkili kararlar şirketleri olumlu etkileyebilir veya bu karar v erme faaliyetlerinde herhangi bir sorun varsa şirketler için olumsuz etkiler olabilir.

Yöntem- Bu çalışmada Stratejik Süreç (Karar Verme ve Hedefler) ile Yönetici ve Şirketlerin Özellikleri arasındaki ilişki araştırılmıştır. Araştırma için örnek olarak Kuzey Kıbrıs'taki beş yıldızlı oteller kullanılmıştır. Metodoloji bölümünde, araştırmacı araştırma katılımcıları için bazı anketler kullanmış ve sonuçlar SPSS (versiyon 23) programı ile analiz edilmiştir.

Bulgular- Çalışmada hipotezlere dayanan teorik bir çerçeve bulunmaktadır. Çalışmanın sonuçları, stratejik süreç ile yöneticilerin ve şirketlerin özellikleri arasında güçlü bir ilişki olduğunu göstermiştir.

Sonuç- Şirketlerin hedefleri ile yöneticilerin ve şirketlerin özellikleri ile güçlü bir ilişki vardır; stratejik karar alma süreci ile hedeflerin belirlenmesi ile yöneticilerin ve şirketlerin özellikleri arasında güçlü bir ilişki olduğu tespit edilmiştir.

Anahtar Kelimeler: Yönetici Özellikleri, Şirket Özellikleri, Karar Verme, Hedefler, Stratejik Süreç JEL Kodları: L83, 015, L10 


\section{Gíriş}

Günümüzde işletmelerin ayakta kalması ve başarılı olması gerçekten zordur. Karar verme süreci ve hedefler işletmelerin başarısını etkileyen bazı stratejik faktörlerdir. Bunlar, yöneticiler tarafından alınması gereken stratejik kararlar ve etkin uygulamalarıdır. Etk ili kararlar işletmeleri başarılı kılarken, etkisiz sonuçlar şirketler için olumsuz olabilir. Karar verme süreci, şirketlerdeki yöneticilerin yönetimsel işlevi için en önemli şeydir (Gonenc, 2007). Dolayısıyla, karar mekanizması her düzeydeki yöneticiler için geçerlidir. Yöneticiler, kararları ile örgütsel işlevlerinin büyük çoğunluğunu yerine getirirler ve bu kararlar kuruluşların davranışlarını şekillendirir ve değiştirir. Hedefler, herhangi bir şirketin ulaşması gereken kısa vadeli hedefler veya görevler hakkında çok daha fazlasını içerir (Bakan, 2008). Bu dönemde stra teji terimi, bu günlük hedefleri uzun vadeye bağlamak ve stratejik süreç oluşturmak için önemli bir rol oynamaktadır (Erkan ve Kılıç, 2006). Örgütlerde alına n stratejik süreç, günlük hayatta alınacak kararlardan çok daha zor ve karmaşıktır. Yöneticilerin aldığı kararları etkileyen ve alınan bu kararların etkinliğini de etkileyen birçok faktör vardır. Karar alma sürecinde hedefl ve stratejileri belirlerken bazı iç ve dış faktörler vardır (Vesk aisri ve diğerleri, 2007). Bunlar karar vericinin özelliklerini, kararlaştırılması gereken problemi, bu faktörlerin alternatifini ve etkilerini içerir. Bu faktörler, herhangi bir şirketin karar alma ve hedefleri olan stratejik süreci doğrudan etkileyen iç faktörler olarak adlandırılabilir. Bunun dışında kararın alındığı ortamın özellikleri ve dinamikleri ile dış çevre faktörleri de stratejik süreci etkilemektedir (Howard ve diğerleri, 2008).

\section{STRATEJIK SÜRECIN IŞLETMELER IÇIN ÖNEMI}

Karar verme ve stratejik hedef belirleme faaliyetleri, herhangi bir işletme organizasyonu için hayati önem taşır. Bu faaliyetler aslında verimlilik ve yönetim için yaratıcılık açısından çok önemlidir. Bu karar verme eylemi işletme yönetiminin kalbi olarak tanımlanmaktadır (Demir ve Mustafa, 2010). Karar verme sürecinde yanlış yol izleyen bir yönetim ayakta kalamazya da iş piyasasırekabetinde herhangi bir rekabetavantaj sağlayamaz. Ayrıca, karar olmadan, herhangi bir idari işlem yapılamaz. Modern işletmelerde karar alma, yönetimin temeli olara k kabul edilir, çünkü iş organizasyonlarında yöneticinin hedefleri ve kararları olan stratejik süreci yönetmede başarı veya başarısızlığa yol açar (Yeşil ve diğerleri, 2011). Hedefler, Herhangi bir şirketin ulaşması gereken kısa vadeli amaçlar ve onlardan çok daha fazlasını içerir. Bu dönemde stratej terimi, bu günlük hedefleri uzun vadeye bağlamak ve stratejik süreç oluşturmak için önemli bir rol oynamaktadır (Kiraz, 2007). Karar Verme Süreci, Karar verici tarafından belirlenen amaçlar için iki veya daha fazla seçenekten birini seçmek anlamına gelir. Açıkça tanımlanabilen ve değerlendirilmesi gereken birden fazla alternatif geliştirilmiştir. Karar alma pozisyonundaki yöneticiler karar verirken bazı operasyonlar gerçekleştirirler. Karar alma, bir hizmetin ne olduğunu, nasıl yapılacağını ve kime hitap edeceğini belirleme faaliyetidir. Bu bağlamda işletme yönetiminde karar alma mekanizmaları ve işlevleri önemlidir (Tekin, 2009). Stratejik süreç için çok önemli olan etkili bir ka rar alma süreci yapratmak için, en iyi kararları seçmek ve her zaman bazı alternatifler yaratmak çok önemlidir. Bu çalışma stratejik karar verme ve hedef belirleme üzerine odaklanmıştır. Stratejik kararlar, üst yönetim ile iş ve çevre arasındaki ilişkiyi düzenleyen geniş kapsamlı kararlardır (Ugboro ve diğerleri, 2011). Bu tür kararlar genellikle işletmenin gelecekteki sistemine yöneliktir. Örneğin, işletmenin uzun vadedeki yani stratejik hedefleri açıkça tanımlanmalı ve alt hedefler yani günlük hedefler kısa vadede gerçekleştirilmek üzere planlanmalıdır. Üretim ve pazarlama ile ilgili kararlar genellikle stratejik kararlar dahilinde alınır (Vaara ve diğerleri, 2010). İşletmeler için amaç ve hedefleri belirle mek, hayati bir önem taşımaktadır. İşletmeler için yaratıcı tavsiyeler veren ve çalışmalar yapan Business Case Studies (2020), bu a maç ve hedefleri belirlemede işletmelerin temel olarak hangi adımlar atması gerektiğini aşağıdaki gibi özetlemiştir. Amaç uzun vadede yani stratejik süreçte başarıya ulaşmak ise, belirlenen bu hedeflere ulaşmak için gereken eylemler günlük hedefler olmalıdır. Bunlar şirketlerin, ne yapması ve ne zaman yapacakları konusunda onlara yol gösteren bir yol haritası gibidir. Hedefler ölçülebilir ve birçoğu aynı amaca yol açabilir (Veal, 2002). Yöneticiler zorluklarla karşılaştığında, uzun vadeli ve kısa vadeli sor unları aşmak bu zorlukları yönetmek ve çözüm üretmek için planlama yapmak zorundadırlar (Reem ve diğerleri, 2014). Kısacası hedefleri koyup, onları açıkça görebildiğinde (yol haritaları oluşturarak), bu hedeflere uzun vadede ulaşmak için planlar yaptıklarında ve bu planlar dahilinde ilerlemeri yakından takip ettiklerinde, işletmeler başarıya ulaşacaklardır (Lerner ve diğerleri, 2015).

\subsection{Stratejik Süreçte Yöneticilerin Özellikleri}

Bu çalışmada ele alınan konulardan biri, yöneticilerin stratejik karar almaya yönelik tutumlarının demografik özellikleri açısından farklılık gösterip göstermeyeceğidir. Bu konuda daha önce yapılan çalışmalar, farklı demografik özelliklere sahip yöneticilerin stratejik karar almalarında farklılıklar gösterdiği kanıtlanmıştır (KelJermanns, 2005). Yöneticilikte yeniliklere açık olmak gerekir. Vizyon sahibi olmanın önemi çalışanlar ve yöneticiler için önemli olduğu kadar üst düzey yöneticiler ve hatta patronlar içinde öğrenilmesi gereken ve sahip olunması gereken bir özelliktir. Üst düzey yöneticilerin kendileri ve kuruluşları için net bir vizyonu olmalıdır. Oraya tam olarak nasıl varacaklarını bilmeseler de eylem ve deney yoluyla yolu bulma konusunda kararlı olmalıdırlar. vizyon sahibi olmak iyi yönetici özellikleri arasında önemli bir yerde durmaktadır (Çivi ve diğerleri, 2008). Başarılı yöneticiler hatalarından ve bu hatalardan alınan derslerden söz ederken sorun yaşamamalıdırlar. (Aktaş, 2015). Eğitim ve deneyim, bireyin en genel anlamda davranışı değiştirme sürecidir. Eğitim sürecinden geçen bireyin davranışında olumlu ve istendik yönde bir değişiklik olması beklenmektedir. Bu bağlamda yöneticilerin demografik özelliklerinin stratejik karar alma sürecini etkilediği söylenebilir (Girard ve diğerleri, 2003). Yöneticiler antik çağlardan itibaren, çalışanlar ve kendileri tarafından yapılması gereken tüm işlerin yapılması için asla yeterli zamana sahip olmadıklarını kabul etmişlerdir. Bununla birlikte, yir minci yüzyılın son yıllarında yeni bir fenomen ortaya çıktı: liderlik rollerinden zaman talebi arttı, bir gün içindeki saat sayısı sabit kaldı. Artan çalışma saatleri bu talebe bir tepkiydi, ancak yöneticiler günün sadece 24 saat olduğunu ve daha fazla çalışmanın azalan marjinal getiri sağladığ ını çabucak keşfettiler. Bir araştırmacıya göre, "Yöneticiler zorunluluklarla aşırı yükümlüdür, ancak görevlerini kolayca devredemezler. Sonuç olarak, aşırı çalışmaya yönlendirilirler ve yüzeysel olarak birçok görev yapmaya zorlanırlar. Zamandaki kısalık, parçalanma ve sözlü iletiş im çalışmalarını karakterize eder." (Mintzberg, 1990). Klasik yönetim teorisi, yedi kişinin bir yöneticinin makul bir şekilde işleyebileceği maksimum doğrudan rapor sayısı olduğunu göstermektedir (Levent, 2020). Günümüzde, yüksek hızlı bilgi teknolojisi ve son derece v erimli telekomünikasyon sistemleri, birçok yöneticinin kendilerine doğrudan rapor veren en azından 20 veya 30 kadar kişiye sahip olduğu anlamına gelir. Verimlilik temel bir beceridir ve yöneticiliğin olmazsa olmaz bir özelliğidir. İhtiyaçlarından daha az zamanla, iş günü boyunca gittikçe daha küçük birimlere bölünmüş zamanla, işyeri birçok yöneticiyi kapıda ve hatta tatilde takip ederken ve küçültülmüş, daha düz kuruluşla rda yöneticilere 
daha fazla sorumluluk yüklendiğinde, verimlilik yirmi birinci yüzyllın temel yönetim becerisi haline gelmiştir. Öte yandan iyi bir yönetici girişimci olmalıdır. Girişimciliğin temelinde, yenilikçilik ve risk alma bu alınan riskleri başarıya çevirme yatmaktadır (Kulakoğlu, 2018). Yöneticiler, çevrelerindeki tehdit ve fırsatların giderek daha fazla farkında olmalıdır. Tehditler arasında rakipler üzerinde teknolojik atılımlar, bir yöneticinin organizasyonunda eskime ve ürün döngülerinin önemli ölçüde kısaltılması yer alıyor. Fırsatlar, yetersiz hizmet alan ürün, hizmet dışı işe alım fırsatları, birleşme, satın alma veya ekipman, alan veya diğer varlıklardaki yükseltmeleri içerebilir (Gürel ve Tat, 2017). Liderler olarak yöneticiler, sürekli olarak kuruluştaki kişilere söz ve potansiyel ile mentor olarak hareket etmelidirler (Doğ ru ve Çakır, 2015) . Şirketler her zaman belli bir zaman aralığında işlevleri maksimum düzeye taşıma hedefindedir (Torlak, 2013). Katz (1974) ve Mintzberg'in 1990 yılındaki tanımları yöneticilik için şu maddeleri öne çıkarmıştır: 1. Uzun vadeli planlama, 2. Kontrol, 3. Çevresel tarama, 4. Kontrol ve koordinasyon, 5. Müşteri ilişkileri, topluluk ilişkileri ve pazarlama, 6. iç danışmanlık, 7. Ürün ve hizmetlerin izlenmesi: 1. Teknik beceriler, 2. Insan ilişkileri becerileri ve 3. Kavramsal becerileri.

\subsection{Stratejik Süreçte Şirketlerin Özellikleri}

Bu çalışmada ele alınan diğer bir konu ise, stratejik sürece yönelik tutumların işletmelerin bazı temel özelliklerine göre de ğişeceğidir. Özelliklere göre değişim gösterebilecek stratejik tutumlar, işletmelerin temel özelliklerinden bazılarını, belirleme hedeflerini ve stratejik karar vermeyi etkilemektedir. İşletmeler birçok açıdan birbirinden farklıdır. Bu nedenle işletmeler farklı şekillerde sınıflandırılıp, kategorilere ayrılabilir (Janczak, 2005). Bu farklılıklar, işletmenin büyüklüğü, faaliyet gösterdiği sektör, çalışan sayısı ve sermaye yapısı gibi birçok faktörü içerir. Yapılan araştırmalar, işletmelerin temel özelliklerinin farklılık gösterdiğini ve bu farklılıkların, işletmelerin str atejik sürece yönelik tutumlarını da farklılaştırdığını göstermektedir (Lamb ve diğerleri, 2006). Bu çalışma aynı zamanda işletmelerin farklı özelliklere sahip olduğunu ve farklı işletmelerde farklı stratejik kararların alınıp, hedefleri berirlemesinde etkili olacağını göstermektedir. İşletmelerin yaşı, sektörlerinde deneyim ve bilgi sahibi olunduğunu göstermektedir (Mfosi, 2006). Öte yandan, yeni kurulan işletmeler farklı organizasyon kültürüne sahip ve yenilikçi kimlikleriyle ön plana çıkabilirler. İşletmelerdeki personel sayısı da bilgi bu özelliklerdendir. Staj ve eğitim programları personele öğretilen değerler farklı organizasyonel kimlikler yaratmaktadır (Misra, 2010). Eğitimler ve onların uy gulanma programları personellerin deneyim ve yetenek kapasitelerindeki artışın bir göstergesidir. En kalifiye personel, yüksek standartlar, karlılık, verimlilik ve şirket yeterliliği ile eş zamanlı bir şekilde üretkenlik yaratacaktır (Smadi ve Al-Jawazneh, 2011). Bu standartlara ulaşmanın en iyi yolu, işe alım faaliyetleri, güçlü oryantasyon ve eğitim, ücretlendirme ve ödüllendirme, denetleme ve gelişimleri takip etme işlevleriyle ön plana çıkan, güçlü İnsan Kaynakları Yönetimi departmanıdır. Öte yandan, farklı işletmelerdeki yatak veya koltuk sayıları, ça lışan, misafir ve personel sayıları ile ortalama gitmelidir (Ozkul et al, 2016). İşletmelerde stratejik karar verme süreçleri, personel bilgi ve deneyimi ile doğrudan bağlantılıdır. Uzmanlaşmış, kalifiye personeller zor zamanlarda daha mantıklı karar verebilecekken, daha doğru hedef belirlerler. Genel olarak, işletmelerin temel özellikleri, bir bilgi, deneyim, beceri ve yetenek duygusuna işaret eden kurumsal hafıza ve kapasite duygusunu temsil eder (Kevser, 2007). İşletmelerde stratejik karar alma süreçlerinin özel ve özgün bilgi, tecrübe ve deneyim olduğu düşünülürse, doğal olarak işletmelerde stratejik karar verme üzerinde bu maddelerin etkileri oluşur. Bu bilgi ve tartışmalar, şirketlerin özellikleri ile stratejik süreçler arasında alınan hedef ve kararlar arasında bir ilişki olduğunu göstermektedir (Wesley ve diğerleri, 2006). Locus Assingments (2020) şirket karakteristiklerini aşağıdaki başlılarla en temel halleriyle açıklamıştır (Sözüer ve diğerleri, 2012). Şirket içindeki yönetici ve çalışanlar dahil tüm ekibin performansına (mutlu bir ortamda çalıştıklarında, olumlu bir şekilde) ve şirketin marketteki imajına yansıyacaktır (Locus Assingments, 2020).

\section{ARAŞTIRMA YÖNTEMLERI}

Araştırman, araştırma yöntemi olarak literatür taramasını kullanmıştır. Bu tip çalışmalar daha önce defalarca ya pılmış olup, birçok araltırmacı hem nitel hem de nicel araştırma yöntemlerini kullanmışlardır. Bu çalışmalarda yer alan açık uçlu ve çoktan seçmeli anketlerle yapılan görüşmeleri içeren karma yöntemler kullanılmıştır. Kuzey Kıbrıs Beş Yıldızlı Oteller çalışmada temel alınarak, oradaki oteller gözlemlenmiş ve araştırmayı güçlendirecek mülakatlar veri olarak çalışmanın sonuç kısmında gösterilmiş ve literatür taramalarını destekleyen çalışma hipotezleri araştırma sonuçları kısmında gösterilmiştir. Araştırmada, Girne beş yıldızlı bir turizm başkenti olduğundan dolayı seçilmiştir. Otelde farklı departmanlardan yöneticilerle görüşmeler yapılmış ve otel çalışanları araştırma sırasında iş ortamlarında izlenmiş ve dolayısıyla bir nevi katılımcı olarak görev almışlardır. Araştırmaya katılanlar arasında Genel Müdür ve Bölüm Müdürleri, Ön Büro Bölümü, Yiyecek \& İçecek Bölümü, Muhasebe Bölümü, Pazarlama ve Satış Bölümü Yöneticileri ile özellikle IKKY - İnsan Kaynakları Yönetimi Bölümü ve bu departmanların yetkili çalışanları bulunmaktadır. Çalışmada demografik veriler ayrıca anket olarak toplanmış ve çoktan seçmeli cevaplar almak için tasarlanmıştır. Açık uçlu görüşme sorularını içeren kısım araştırma sonuçlarında detaylandırılmıştır. Açık uçlu sorulara yöne ticiler soru-cevap yani mülakat şeklinde cevap vermişlerdir Bilgiler SPSS 23 sürümü ile analiz edilmiştir. Bu sorulara cevap veren kişiler ve pa ylaşımları gizli tutulmaktadır.

\section{ARAŞTIRMA SONUÇLARI}

Sonuçlar, farklı yöneticilere ait farklı demografik özelliklerin, stratejik karar verme sürecini etkilediğini göstermiştir. A raştırmalardan elde edilen bilgi ve tartışmalar, şirketlerin özellikleri ile stratejik süreçler arasındaki hedef ve karar alma süreçleri arasında bir ilişki olduğunu göstermektedir. Ayrıca, Yöneticilerin ve Şirketlerin Özellikleri ile Stratejik Süreç arasında bir ilişki vardır; Yöneticilerin ve Şirketlerin Özellikleri ile şirketlerin hedefleri arasında bir ilişki vardır; Karar verme süreci ile Yöneticilerin ve Şirketlerin Özellikleri arasında bir ilişki vardır. Tüm bu ilişkiler birbirini etkilemektedir. Çalışmanın teorik çerçevesi, Yönetici ve Şirketlerin Karakteristiklerindeki farklııkları bağımsız değişken; Otel endüstrisinde stratejik süreçlerin (hedef ve karar verme süreci) bağımlı değişken olduğunu göstermektedir. Kısacası, bağımsız değişken (yöneticilerin ve şirketlerin özellikleri) organizasyonel kültürel faktörler, demografik yönetim faktörleri vb. ile farklı şirket türlerini içerir ve bunlar bağımsız değişkenlerdir. Kuzey Kıbrıs' taki 5 Yıldızlı Otel İşletmelerinde görevli departmanyöneticileri üzerinde yapılmış olan bu çalışma, mülakat sorularını (yapılan yorumlara sonuç kısmında ayrıca yer verilmiştir) içermektedir. Birincil veri toplama aracı olarak demografik bilgi 
toplama soruları otel yöneticilerine uygulanmıştır. Bunun dışında literatür taraması yapılmış yukarıda açıklanan hipotezler oluşmuş, daha sonra konuyla ilgili yönetici yorumları çalışmayı desteklemektedir.

\section{SONUÇ}

Bu çalışmada, yönetimsel demografik özellikler ile işletmelerin stratejik karar verme süreçleriyle ilgili bazı temel özellikleri, hedefleri ve karar verme sürecini belirleyen stratejik süreçler üzerindeki etkiler araştırılmıştır. Literatür taramasında ve anket sorularına verilen cevaplarda şirketlerin ve yönetici karakteristiklerinin stratejik süreçleri (hedefleri ve karar verme süreçlerini) doğrudan etkilediği ve iyi yönetici tipleriyle, düzgün ve iyi işletilen (uygulamaları örneklendirilmiş çalışmalardaki gibi sağlam olan) işletmelerin bu süreçten olumlu etkilendiği, zayıf karakterli ve çalışmada paylaşılmış doğru yönetici profilinden uzak (yanlış profillerden oluşan) yönetici profillerinin ve personeline önem vermeyen işletmelerin bu süreçten olumsuz etkilendiği görülmüştür. Çalışma, Kuzey Kıbrıs'ta yapılan bir alan araştırmasıyla desteklenmiştir. Turizmin başkentlerinden biri olan Girne, ve orada bulunan beş yıldızlı oteller araştırma bölgesi olarak kullanılmıştır. Araş tırmanın katılımcıları ve veri sağlayıcıları olarak yönetici ve çalışanlar kullanılmıştır. Sonuçlar, stratejik sürecin yöneticilerin ve şirketlerin karakteristik özelliklerinden etkilendiğini göstermektedir. Çalışmada yer alan teorik çerçevede bağımsız değişken (yöneticilerin ve şirketlerin özellikleri) organizasyonel kültürel faktörler, demografik yönetim faktörleri vb. ile farklı şirket türleridir; bağımlı değişken ise hedefleri ve karar verme sürecini içine alan stratejik süreçtir. Çalışmanın sonuçları, yöneticilerin ve şirketlerin stratejik süreçle özellikleri arasında güçlü bir ilişki olduğunu göstermiştir; şirketlerin hedefleri ile yöneticilerin ve şirketlerin özellikleri; stratejik karar alma süreci ve hed eflerin belirlenmesi ile yöneticilerin ve şirketlerin özellikleri arasında güçlü bir ilişki olduğu saptanmıştır.

\section{REFERANSLAR}

Aktan, C., and Vural, I. Y. (2004a). Rekabet Dizisi: 2 Rekabet Gücü ve Rekabet Stratejileri, Ankara: Türkiye Işveren Sendikaları Konfederasyonları Yayını, Yayın, (254), 9-23.

Aktaş, K. (2015). Uluslarası İşletmelerde Stratejik Yönetim, Uluslarası Yönetim ve Sosyal Araştırmalar Dergisi, 3(1), 16.

Çivi, E., Erol, İnanlı, T., ve Erol, E. D. (2008). Uluslararası rekabet gücünde farklı bakışlar. Ekonomik ve Sosyal Araştırmalar Dergisi.

Bakan, I. (2008). Örgüt kültürü ve liderlik türlerine ilişkin algılamalar ile yöneticilerin demografik özellikleri arasındaki ilişki: bir alan araştırması. Kahraman Maraş Üniversitesi IïBF Dergisi, 10 (14), 13-40.

Demir, C. ve Mustafa K. Y., "Stratejik Planlama Süreci ve Örgütler Açısından Önemi”, Dokuz Eylül Üniversitesi Iktisadi ve Idari Bilimler Fakültesi Dergisi, Cilt:25, Sayı:1, Yıl:2010, ss. 69-88.

Doğru, G. ve Çakır, S. Y., (2015). IŞVEREN MARKASI YÖNETIM SÜRECINDE STRATEJi VE UYGULAMALARIN INCELENMESI: TÜRKIYE'DEKI ŞIRKETLERIN INSAN KAYNAKLARI YÖNETICILERINE YÖNELIK BIR ARAŞTIRMA, The Journal of International Social Research. 40 Volume: 8 IsSUe: 40, October, 2015. www.sosyalarastirmalar.com Issn: 1307-9581.

Girard, T., Korgaonkar, P., \& Silverblatt, R. (2003). Relationship of types of product, shopping orientations and demographics with preference for shopping on the internet. Journal of Business and Psychology, 18(1). 101-120.

Goeldner, C. R., \& Ritchie, J. B. (2003). Tourism: Principles, Practices, Philosophies. New Jersey: John Wiley \& Sons.

Gönenç, Etkhem-John Wolflin, 2007. Sustainability, Sustainable Management and Decision Making Process, Strategic Process Marmara Environmental Master Plan and Investment Strategy, İstanbul, 2007.

Gürel, E. ve Tat, M. (2017) SWOT ANALYSIS: A THEORETICAL REVIEW Uluslararası Sosyal Araştırmalar Dergisi The Journal of International Social Research. Cilt: 10, Sayı: 51, Volume: 10, Issue: 51, Ağustos 2017 www.sosyalarastirmalar.com Issn: 1307-9581 Doi Number: http://dx.doi.org/10.17719/jisr.2017.1832

Howard C. Kunreuther \& David H. Krantz, 2008. Judgment and Decision Making, Vol. 2, No. 3, June 2007, pp. 137-168 Goals and plans in decision making Department of Psychology Columbia University \& The Wharton School University of Pennsylvania.

Ibrahim, Zainub and Wall, Geoffrey, "Assessing Tourism Planning: Goals and Objectives for Egyptian Tourism" (2016). Travel and Tourism Research Association: Advancing Tourism Research Globally. 44. https://scholarworks.umass.edu/ttra/2011/Oral/44

Janczak S. (2005): "The Strategic Decision-Making Process in Organizations". Problems and Perspectives in Management, 3/2005.

Katz, Robert L., (1974). "Skills of an Effective Administrator." Harvard Business Review, September -October 1974.

KelJermanns, F. W. - Walter, J. - Lechner, C. - Floyd, S. W. (2005), "The Lack of Consensus about Strategic Consensus: Advancing Theory and Research", Journal of Management, Vol. 31, No: 5, October, p. 719-737.

Kevser, M. (2007): “Stratejik Planlama ve KOBi'lerdekiUygulamalar Üzerine Bir Araștırma, ” Yüksek Lisans Tezi, Dokuz Eylül Üniversitesi, Sosyal Bilimler Enstitüsü, İzmir.

Kılıç, M., Erkan, V. (2006): “Stratejik Planlama ve Dengeli Performans Yöntemi Yaklaşımı Bir Arada Olabilir Mi?” Ticaret ve Turizm Eğitim Fakültesi Dergisi, 2 77-93. 
Kiraz, M. (2007): “Örgütlerde Stratejik Planlama Sisteminin Oluşturulması ve Emniyet Genel Müdürlügünnde Bir Uygulama," Yüksek Lisans Tezi, Gazi Üniversitesi, Eğitim Bilimleri Enstitüsü, Ankara.

Lamb, C. J., Lachow I. - Reforming Pentagon Strategic Decision-making, Institute for National Strategic Studies, July 2006.

Lerner, J. S., Li, Y., Valdesolo, P., \& Kassam, K. S. (2015). Emotion and decision-making. Annual Review of Psychology, 66. doi:10.1146/annurevpsych-010213-115043.

Levent, F. (2020). Yönetim Teorileri ve Yeni Yönetim Yaklaşımları.

Locus Assingments, (2020). Characteristics of a Company, Locus Assingments, Retrieved from: https://www. locusassignments. com.

Lysonski, S., Durvasula, S., \& Zotos, Y. (1996). Consumer decision-making styles: a multi country investigation. European Journal of Marketing, 30(12), 10-21.

Makgosa, R. (2014). The Role of Demographics on Decision-Making Styles of Botswana's Retail Shoppers, Research in Business and Management ISSN 2330-8362 2014, Vol. 1, No. 2.

Makgosa, R., \& Mfosi, T. (2006). Gender and decision-making styles of young adult consumers in Botswana: Implications for marketing practitioners. Journal of Business Management and Training, 3(2), 25-46.

Mintzberg, H. (1990). "The Manager's Job: Folklore and Fact." Harvard Business Review, March-April 1990, p. 167.

Mishra, A. A. (2010). Consumer decision-making styles and young-adult consumer: An Indian exploration. Isletme Arastirmalari Dergisi, 2(3), 45-62.

Ozkul, E., Arif Gungor, Sedat C., Pelin Fatma Tuna, 2016. The Relationship Between Strategic Decision-Making and Leadership Styles: An Application in 4 and 5-Star Hotels in Istanbul. Journal of Business Research Turk. IAD, Isletme Arastirmalari Dergisi - ISSN: 1309 - 0712. Retrieved from, IAD - (www. isarder).

Poister, T. H., \& Streib, G. (2005). Elements of strategic planning and management in municipal government: Status after two decades. Public Administration Review, 65, 45-56. doi:10.1111/j.1540-6210.2005.00429.x

Reem, A. D., Kitsantas, P., \& Maddox, P. J. (2014). The impact of residency programs on new nurse graduates' clinical decision-making and leadership skills: A systematic review. Nurse Education Today, 34(6), 1024-1028. doi:10. 1016/j.nedt.2013.10.006

Smadi, Z. M., \& Al-Jawazneh, B. E. (2011). The consumer decision-making styles of mobile phones among the University level students in Jordan. International Bulleting of Business Administration, 10, 104-121.

Sozuer, Aytug \& Gökçen, Zeynep \& Arslantaş, Cem. (2012). Yönetim kurulu özellikleri ve şirket performansları: iMKB Kurumsal Yönetim ve IMKB 50 endekslerindeki işletmelerin karşılaştııılması. İşletme iktisadı Enstitüsü Dergisi Yönetim. 23. 77-89.

Tekin, Ilker, Study on the Place of Business Strategic Planning at Decision-Making Levels and Its Application to Commercial Banks, Süleyman Demirel Üniversitesi, Yüksek Lisans Tezi, Isparta. (Unpublished) 2009.

Tekin, Ö. A. ve Ehtiyar, R. (2010). Yönetimde karar verme: Batı Antalya bölgesindeki beş yıldızı otellerde çalışan departman yöneticilerinin karar verme stilleri üzerine bir çalışma. Journal of Yaşar University, 20(5), 3394-3414.

Torlak, N. Gökhan. (2013). Organizasyonlarda Strateji Yönetimi.

Ugboro, I. O., Obeng, K., \& Spann, O. (2011). Strategic planning as an effective tool of strategic management in public sector organizations: Evidence from public transit organizations. Administration \& Society, 43, 87-123. doi:10.1177/0095399710386315

Vaara, E., Sorsa, V., \& Pälli, P. (2010). On the force potential of strategy texts: A critical discourse analysis of a strategic plan and its power effects in a city organization. Organization, 17, 685-702. doi:10.1177/1350508410367326

Veal, A. (2002). Leisure and Tourism Policy and Planning. Wallingford: CABI Publishing.

Veskaisri, K., Chan, P, \& Pollard, D. (2007). "Relationship Between Strategic Planning and SME Success: Empirical Evidence from Thailand", Conference of the International Decision Sciences Institute (DSI) / the 12th AsiaPacific DSI Conference Full Paper, July, ss. 1-13.

Wesley, S., LeHew, M., \& Woodside, A. G. (2006). Consumer decision-making styles and mall shopping behaviour: building theory using exploratory data analysis and the comparative method. Journal of Business Research, 59(5), 535-548.

Yesil, Salih \& Ersahan, Esra 2011. Decision Making Process in Hotel Accommodations and the Demographic Characteristics of Managers and the Companies. Organizasyon ve Yonetim Bilimleri Dergisi. Cilt 3, Sayı 2, 2011 ISSN: 1309 -8039 (Online).

Zehir, C. ve Özşahin, M. (2006). Stratejik karar verme hızını etkileyen örgütsel, çevresel faktörler ve firma performansı ilişkisi: imalat sektöründe bir saha çalışması, Gazi Üniversitesi iktisadi ve Idari Bilimler Fakültesi Dergisi, (9). 137- 157. 